\title{
Vault Immunofluorescence in the Brain: New Insights Regarding the Origin of Microglia
}

\author{
Diane C. Chugani, ${ }^{1}$ Nancy L. Kedersha, ${ }^{2}$ and Leonard H. Rome ${ }^{2}$ \\ 'Division of Nuclear Medicine, Department of Radiological Sciences, and 'Department of Biological Chemistry and the \\ Mental Retardation Research Center, UCLA School of Medicine, Los Angeles, California 90024
}

\begin{abstract}
The developmental appearance of ameboid and ramified microglia in the rat brain has been examined by immunofluorescent localization of vaults, recently described ribonucleoprotein particles (Kedersha and Rome, 1986a). Vaults are distinct, multiarched structures of unknown function expressed by higher and lower eukaryotic species. Although vaults have been detected in all mammalian cells examined to date, they are highly enriched in macrophages. In the brain, vault antisera is highly specific for both ameboid and ramified microglia. The developmental protile of vault immunoreactivity in rat brain slices suggests that microglia enter the brain at 2 locations, with different time scales for each. The first migration, which begins before embryonic day 15 and subsides between postnatal days 7 and 14, was identified by vault immunoreactivity and Bandeiraea simplicifolia $\mathrm{B}_{4}$-isolectin (a microglia marker) staining. The cells appear to enter from blood vessels and display a ramified morphology as soon as they are detected in the brain. The second microglial migration occurs in the first postnatal week, when ameboid microglia appear in the corpus callosum and other large fiber tracts. Ameboid microglia appear to differentiate into ramified microglia between postnatal days 4 and 14. Vault immunoreactivity, as a very early microglial marker, provides new insight regarding the much-debated origin of the ramified microglia. It is quite clear that ameboid cells are not the sole source of ramified microglia because ramified cells can be detected before the influx of ameboid microglia. Colocalization studies with monocyte/macrophage markers ED1 and OX42 demonstrate that both ramified and ameboid microglia originate from monocyte lineage.
\end{abstract}

Microglia are believed to be the mediators of immune responses in the CNS. Morphologically, there are 2 types of microglia: (1) ameboid microglia, also known as gitter cells and reactive microglia, which are round, macrophagelike phagocytic cells with pseudopodia; and (2) ramified microglia, which are small cells with fine, crenulated, branching processes. A large body of evidence suggests that the ameboid microglia, like other tissue macrophages, are derived from blood-borne monocytes (for re-

\footnotetext{
Received May 14, 1990; revised Aug. 30, 1990; accepted Sept. 10, 1990.

We wish to thank Mithra Mahmoudi for excellent technical assistance and Drs. Thomas Babb and Jean Merrill for helpful comments on this manuscript. This work was supported by NIH Grants NS 15654, GM 38097, and HD 06576 and by DOE Grant DE-FC03-87ER60615.

Correspondence should be addressed to Diane C. Chugani, Ph.D., Division of Nuclear Medicine, Department of Radiological Sciences, UCLA School of Medicine, Los Angeles, CA 90024.

Copyright $\odot 1991$ Society for Neuroscience 0270-6474/91/010256-13\$03.00/0
}

view, see Ling, 1981). There is considerable controversy, however, over the origin of the ramified microglia. Rio-Hortega (1932), who originally visualized microglia with silver carbonate, suggested that the ramified microglia result from differentiation of ameboid microglia. While a large number of investigators support this view, there is at least an equal number who deny a relationship between ameboid microglia and ramified microglia.

Ameboid microglia appear in the brain in the late embryonic and early postnatal period and are located primarily in the corpus callosum and other large fiber tracts. It has been proposed that they enter these tracts to remove excess fibers produced during this period of development prior to myelination (Innocenti et al., 1983a,b; Matsumoto and Ikuta, 1985; Perry et al., 1985). Ameboid microglia are also visualized in the injured adult brain, presumably to remove debris. It has also been suggested that factors released from ameboid microglia regulate astroglial proliferation (Giulian and Baker, 1985). The source of the ameboid microglia has been shown unambiguously to be blood-borne monocytes that can invade the normal brain during a narrow window of early brain development (Ling et al., 1980). They disappear from the brain parenchyma by the second postnatal wcck, accompanied by the appearance of ramified microglia. There are 2 schools of thought about the source of macrophages at the site of brain damage. One theory is that quiescent, ramified microglia are activated and become macrophages, whereas others discount a relationship between ameboid and ramified microglia, claiming that macrophages enter the injured brain directly from the blood.

It was the disappearance of the ameboid cells followed by the appearance of "transitional" cells and ramified microglia stained by silver carbonate that lead Rio-Hortega (1932) to suggest that ramified microglia evolved from ameboid cells. Indeed, more contemporary studies have established that ramified microglia possess a number of markers for cells of monocytic lineage. They are, however, negative for a number of other monocyte/ macrophage markers. While the function of ramified microglia is not known, it has been proposed that they play a role in antigen presentation and other immune functions because they express molecules of the major histocompatibility complex (Ia; Hickey and Kimura, 1988), trypsin-resistant IgG1/IgG2b mouseFc and complement type 3 receptors (Perry et al., 1985). In addition, it has been proposed that microglia play a role in neuronal repair with the $\mathrm{C} 3 \mathrm{bi}$ receptor (a member of the integrin family), acting as an adhesion molecule between the neuronal and microglial membranes (Graeber et al., 1988).

In this study, new information regarding the origin of ramified microglia has been obtained using an antiserum raised against 
vaults, recently described ribonucleoprotein particles (Kedersha and Rome, 1986a). These distinct multiarched particles contain 4 major proteins of $M_{r} \mathrm{~s} 210,000,192,000,104,000$, and 54,000, and one small RNA of $M_{r} 37,000$. While the function of vaults is not known, vaults are highly conserved structures that are expressed by higher and lower eukaryotic species, including human, rat, cow, chicken, frog, and the slime mold Dictyostelium discoideum (Kedersha et al., 1990).

Although vaults have been detected in all cell types examined to date, they are highly enriched in macrophages (N. Kedersha and D. Chugani, unpublished observations). In the brain, antivault serum is highly specific for both ameboid and ramified microglia. Described below are studies on the distribution of vault immunoreactivity in cultured microglia and the developing rat brain and its colocalization with established microglial markers ED1 (Dijkstra et al., 1985), OX42 (Robinson et al., 1986), and Bandeiraea simplicifolia $\mathrm{B}_{4}$-isolectin (Streit and Kreutzberg, 1987).

\section{Materials and Methods}

Antibody production and characterization. Vaults were purified from rat liver microsomes, and vault antiserum was prepared in a rabbit designated $\mathrm{N} 2$ as described by Kedcrsha and Rome in a rabbit designated G1 (1986a,b). Briefly, purified intact vaults were mixed with hemocyanin and cross-linked with glutaraldehyde, emulsified in Freund's complete adjuvant, and injected subcutaneously into rabbits. Subsequent boosts were made using vaults (without hemocyanin) emulsified in Freund's incomplete adjuvant. The IgG fraction was isolated from whole serum using Protein A Sepharose (Pharmacia) and, subsequently, passed over a column of purified vaults coupled to agarose (A5M, Biorad Laboratories, Richmond, CA) using cyanogen bromide (Porath, 1974) and stabilized by brief treatment with glutaraldehyde. The column was washed extensively with TBS buffer ( $50 \mathrm{~mm}$ Tris, pH 7.4, $0.15 \mathrm{M} \mathrm{NaCl}$ ) until the $\mathrm{OD}_{280}$ of the eluant was less than 0.10 , then eluted with $0.1 \mathrm{M}$ glycine $(\mathrm{pH}, 3.0)$. The eluted fractions were immediately neutralized with $1.5 \mathrm{M}$ Trizma base and quantitated by UV spectroscopy $\left(\mathrm{E}_{280}=\right.$ $1.2 \mathrm{OD}$ units per $\mathrm{mg} / \mathrm{ml} \mathrm{IgG})$. Antibodies against the major vault protein, p104, were also prepared using a blot affinity approach. Vault proteins were separated on SDS-PAGE, transferred to nitrocellulose, and identified by staining with Ponceau red, and the p104 region was cut from the blot. This nitrocellulose strip was blocked with $5 \%$ nonfat dry milk, incubated with 1:50 dilution of anti-vault serum, and washed with $0.1 \%$ Triton X-100 prior to glycine elution as above. An unrelated protein ( $\beta$-galactosidase) bound to nitrocellulose was used as a control.

Normal rat skin fibroblasts were metabolically labeled overnight with ${ }^{35} \mathrm{~S}$-methionine, chilled, harvested using treatment with trypsin, washed, and frozen. The thawed cell pellet was homogenized in $20 \mathrm{~mm}$ Tris $(\mathrm{pH}$, 7.4), $50 \mathrm{~mm} \mathrm{NaCl}$, and $0.5 \%$ Nonidet $\mathrm{P} 40$ containing the protease inhibitors aprotinin $(5 \mu \mathrm{g} / \mathrm{ml})$, leupeptin $(5 \mu \mathrm{M})$, chymostatin $(5 \mu \mathrm{g} / \mathrm{ml})$, pepstatin $(5 \mu \mathrm{M})$, and soybean trypsin inhibitor $(5 \mu \mathrm{g} / \mathrm{ml})$. The cell extract was centrifuged in an Eppendorf microfuge for $10 \mathrm{~min}$, and the supernatant was pretreated with preimmune serum for $3 \mathrm{hr}$ at $4^{\circ} \mathrm{C}$. Protein A Sepharose was added and the incubation continued for an additional hour, then the extract was centrifuged as above. Antibodies (described in figure legends) were then added to the supernatant and incubated for 2-3 $\mathrm{hr}$ at $4^{\circ} \mathrm{C}$. Protein A Sepharose was added during the last hour of incubation, and the bound immune complexes were pelleted through $30 \%$ sucrose in the above buffer and washed 3 times with the homogenization buffer containing $0.5 \%$ deoxycholate and $0.1 \%$ SDS. The immune complexes were then boiled in SDS sample buffer and subjected to SDS-PAGE (Laemmli, 1970; with modifications described in Kedersha and Rome, 1986a) and fluorography using Autofluor (National Diagnostics, Manville, NJ). Kodak XAR film was used; typical exposures were 3-6 d.

Immunoblot analysis was performed on the small intestine dissected from an adult male rat. Tissue was immediately homogenized in $9 \mathrm{vol}$ of ice-cold buffer containing $20 \mathrm{mM}$ MES [2-( $N$-morpholino $)$ ethane sulfonic acid; Research Organics, Inc.; $\mathrm{pH}, 6.5$ ], $0.2 \%$ Triton $\mathrm{X}-100$, and the protease inhibitors listed above. SDS and DTT were added to the crude homogenates to final concentrations of $2 \%$ and $20 \mathrm{~mm}$, respec- tively. The samples were boiled for $15 \mathrm{~min}$ and cleared by centrifugation, and equal amounts were loaded onto the SDS gel. Western blots were performed as described by Towbin et al. (1979). Whole antiserum was used at a dilution of 1:2000, and affinity-purified antibodies were used at a concentration of $0.5 \mu \mathrm{g} / \mathrm{ml}$.

Immunofluorescence: cultured microglia and mixed glia. Cultured brain macrophages were prepared from postnatal day 2 rat pups by a modification of the procedure of McCarthy and de Vellis (1980) described by Giulian and Baker (1986). Fixed $E$. coli was added to some cultures $1 \mathrm{~d}$ after purification to test the phagocytic ability of the cells. These cells were fixed $24 \mathrm{hr}$ later for $5 \mathrm{~min}$ with $4 \%$ paraformaldehyde and permeabilized for $5 \mathrm{~min}$ with $-20^{\circ} \mathrm{C}$ methanol. Other cells were fixed and permeabilized for $5 \mathrm{~min}$ in $-20^{\circ} \mathrm{C}$ methanol after 1 or $7 \mathrm{~d}$ in culture. Mixed glial cultures were prepared as described by McCarthy and de Vellis (1980) and were fixed and permeabilized in $-20^{\circ} \mathrm{C}$ methanol for $5 \mathrm{~min}$ after $14 \mathrm{~d}$ in culture. Polyclonal rabbit antisera (rabbit N2) was raised against vaults and characterized as described above. EDI and OX42 were purchased from Bioproducts for Science (Indianapolis, IN). ED1 was raised against rat spleen cells and recognizes rat monocytes, macrophages, and dendritic cells (Dijkstra et al., 1985). Sminia et al. (1987) reported that ED1 stained 2 populations of macrophages in the brain: those in the choroid plexus and meninges at all stages of development, and ameboid microglia that appeared in the cerebral hemispheres after birth and gradually disappeared between postnatal days 8 and 12 . OX42 was produced by immunization with rat resident peritoneal macrophages and was shown to react against most macrophages, including resident peritoneal macrophages, alveolar macrophages, Kupffer cells, and microglia (Robinson et al., 1986). In addition, Robinson et al. (1986) identified the antigen recognized by OX42 as the receptor for the complement component $\mathrm{C} 3 \mathrm{bi}$.

Fluorescein isothiocyanate (FITC)-conjugated Bandeiraea simplicifolia $\mathrm{B}_{4}$-isolectin $\left(\mathrm{B}_{4}\right.$-lectin) was purchased from Sigma. FITC-conjugated $B_{4}$-lectin has been shown to be a selective histochemical reagent for the detection of $\alpha$-D-galactopyranosyl groups. $\mathrm{B}_{4}$-lectin has been shown to be a specific label for microglia and blood vessels in the brain and spinal cord by Streit and Kreutzberg (1987).

Fixed cells were incubated at room temperature for $1 \mathrm{hr}$ in $5 \%$ normal goat serum in phosphate-buffered saline, followed by $2 \mathrm{hr}$ in vault antisera (1:500 or 1:1000 dilution) and/or ED1 monoclonal antibody (1: 100 dilution) or OX42 monoclonal antibody (1:100 dilution) and/or FITC-conjugated $B_{4}$-lectin $(50 \mu \mathrm{g} / \mathrm{ml})$. Preimmune rabbit antisera controls, used at the same concentrations as vault antisera, were routinely run and were consistently negative (not shown). Mouse $\mathrm{IgG}$, as well as monoclonal antibodies directed against multiple antigens with different patterns of staining, served as controls for the monoclonal antibodies. Sections were washed $3 \times 10 \mathrm{~min}$ in phosphate-buffered saline, followed by $1 \mathrm{hr}$ incubation with goat anti-rabbit FITC or rhodamine-conjugate (1:200 dilution) and/or goat anti-mouse FITC or rhodamine conjugate (1:200 dilution; Boehringer-Mannheim). In addition to the antibodies listed above, myelin basic protein monoclonal antibody (oligodendrocyte marker; Boehringer-Mannheim), glial fibrillary acidic protein monoclonal antibody (marker for astrocytes; Boehringer-Mannheim), and monoclonal andibody OL28 (a putative neuronal marker; Kedersha and Chugani, unpublished observations) were used to ascertain the purity of the cultures. All antibodies were diluted in $5 \%$ normal goat serum in phosphate-buffered saline. Fixed $E$. coli was detected with bisbenzimide (Sigma) included with the secondary antibody. The stained cells were finally rinsed $3 \times 10 \mathrm{~min}$ in phosphate-buffered saline and mounted with Gelvatol mounting media (Fukio et al., 1987). Specimens were viewed on a Nikon Microphot FX microscope equipped with epifluorescence optics and appropriate filters for the detection of fluorescein and rhodamine.

Immunofluorescence: brain sections. Sprague-Dawley rats (obtained from our own breeding colony) aged $1,3,4,7,14,21$, and $180 \mathrm{~d}$ were anesthetized with halothane and perfused through the left cardiac ventricle with $4 \%$ paraformaldehyde in phosphate-buffered saline. Brains were removed $2 \mathrm{hr}$ following perfusion and cryoprotected in sucrosc. Embryonic rats aged $15 \mathrm{~d}$ were fixed by immersion in $4 \%$ paraformaldehyde for $24 \mathrm{hr}$, followed by cryoprotection in sucrose. Twenty-micron frozen sections were cut on a cryostat and thaw mounted on gelatincoated slides. Immunofluorescence was performed as described above.

Western blot analysis. Cerebral hemispheres were dissected from rats aged $1,2,3,4,5,6,7,10,14,21$, and $180 \mathrm{~d}$ and homogenized in $5 \mathrm{vol}$ (w/v) 20 mM MES buffer $\mathrm{pH}, 6.5$ containing $0.2 \%$ Triton-X 100 . Homogenates were centrifuged at $2000 \times g$ for $10 \mathrm{~min}$ to remove nuclei. 
Figure 1. Specificity of vault antibodies. $A$, Immunoprecipitates using vault antibodies. Normal rat kidney fibroblasts were metabolically labeled and processed as described in Materials and Methods and subjected to SDS-PAGE and fluorography. Lane 1, vault antiserum from rabbit $\mathrm{G} 1$; lane 2 , preimmune serum from rabbit G1; lane 3, anti-vault IgG, column purified from rabbit $\mathrm{N} 2$ against intact vaults; lane 4 , preimmune IgG from rabbit $\mathrm{N} 2$; lane 5 , N2 anti-vault antibody, blot purified against vault p104 protein; lane $6, \mathrm{~N} 2$ vault antiserum blot purified against $\beta$-galactosidase. $B$, Immunoblot showing the specificity of rabbit N2 vault antibodies. Total rat intestine protein extract was probed with both affinitypurified and whole N2 antiserum. Lane 7 , preimmune $\mathrm{IgG}$; lane 8 , anti-vault IgG, column-purified IgG against intact vaults; lane 9, anti-vault IgG, blot purified against vault p104; lane 10, anti-vault IgG, blot purified against $\beta$-galactosidase (as a control); lane 11 . preimmune whole serum; lane 12, antivault whole serum. The arrow indicates the mobility of p104; arrowheads indicate $\mathrm{p} 210$ and $\mathrm{p} 192$.

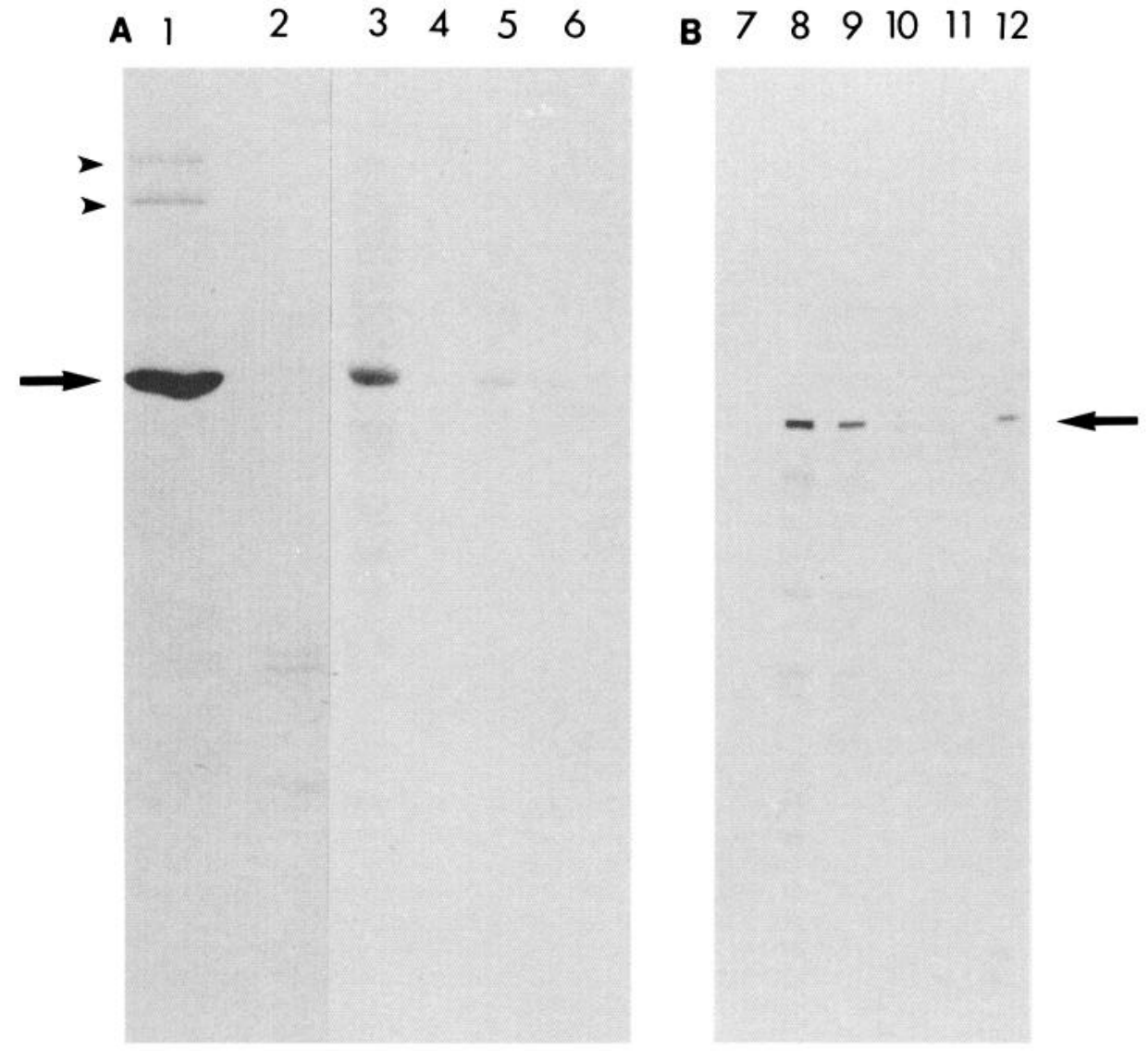

Supernatants were immediately boiled $(10 \mathrm{~min})$ in $0.2 \mathrm{M}$ DTT and $1 \%$ SDS and analyzed on polyacrylamide slab gels as described by Laemmli (1970). Western blot analysis was performed as described by Towbin et al. (1979).

\section{Results}

\section{Specificity and characterization of antiserum}

The antiserum raised against vaults specifically precipitated the major vault polypeptide of $M_{r} 104,000$ (p104) in addition to the other minor vault polypeptides of $M_{r} 210,000$ (p210) and 194,000 (p194) from metabolically labeled whole-cell extracts (Fig. 1, lane 1). The precipitation of the p210 species is noteworthy because this antibody does not recognize this species on Western blots of purified vaults (data not shown), suggesting that p210 is precipitated due to its strong affinity for p104.

Vault antiserum was affinity purified by 2 different methods. Antibodies specific for intact vaults were prepared using a column of whole vaults, while antibodies specific for the major vault protein p104 were purified from p104 bound to nitrocellulose. Both column-purified and blot-purified antibodies precipitated the major vault protein of p104 (Fig. 1, lanes 3, 5) as well as the p210 and p192 polypeptides. While p210 and p192 are not clearly visible on the fluorogram shown, they were seen in other precipitations (data not shown). The column-purified antibody was more efficient in immunoprecipitations than antip104, probably due to better recognition of native epitopes.

The specificity of the antibodies was also assayed by immunoblot analyses against total protein extracts of the rat small intestine (Fig. 1, lanes 7-12), a rich tissue source of vaults.
Preimmune IgG (Fig. 1, lane 7) and preimmune serum (Fig. 1, lane 11) showed no detectable reactivity, while immune serum (Fig. 1, lane 12) and both column-purified and anti-p104 (Fig. 1 , lanes 8,9 ) reacted with a single major species with an apparent mobility equal to the p104 major vault protein. Minor bands of faster mobility were also observed, several of which were recognized by both the column-purified and the blot-purified antibodies, suggesting that these minor bands may arise from the p104 or are related polypeptides. Neither the preimmune sera, the preimmune IgG, nor the vault antiserum blot-purified against $\beta$-galactosidase showed detectable activity on immunoblots (Fig. 1, lanes 11, 7, and 10, respectively). Because the immune serum was judged to be monospecific, whole-vault antiserum was used for the remainder of the study.

\section{Immunofluorescence in microglia and mixed glial cultures}

Microglia cultures, purified from mixed glia on postnatal day 9, contained 90-95\% macrophagelike ameboid shaped cells $1 \mathrm{~d}$ after purification. These cells were able to phagocytically ingest fixed bacteria. Contaminating astrocytes, oligodendrocytes, and neurons constituted the remaining cells. Ameboid microglia in these early cultures were intensely stained with vault antibody. After 1 additional week in culture, approximately half of the ameboid cells differentiated into process-bearing cells resembling ramified microglia (Fig. $2 A-C$ ). Both cell types contained cytoplasmic vault staining in a fine punctate pattern, which has been previously seen in a variety of cell types (N. Kedersha, unpublished observations), though the ameboid cells were somewhat more intensely stained (Fig. 2A). Both ameboid and 

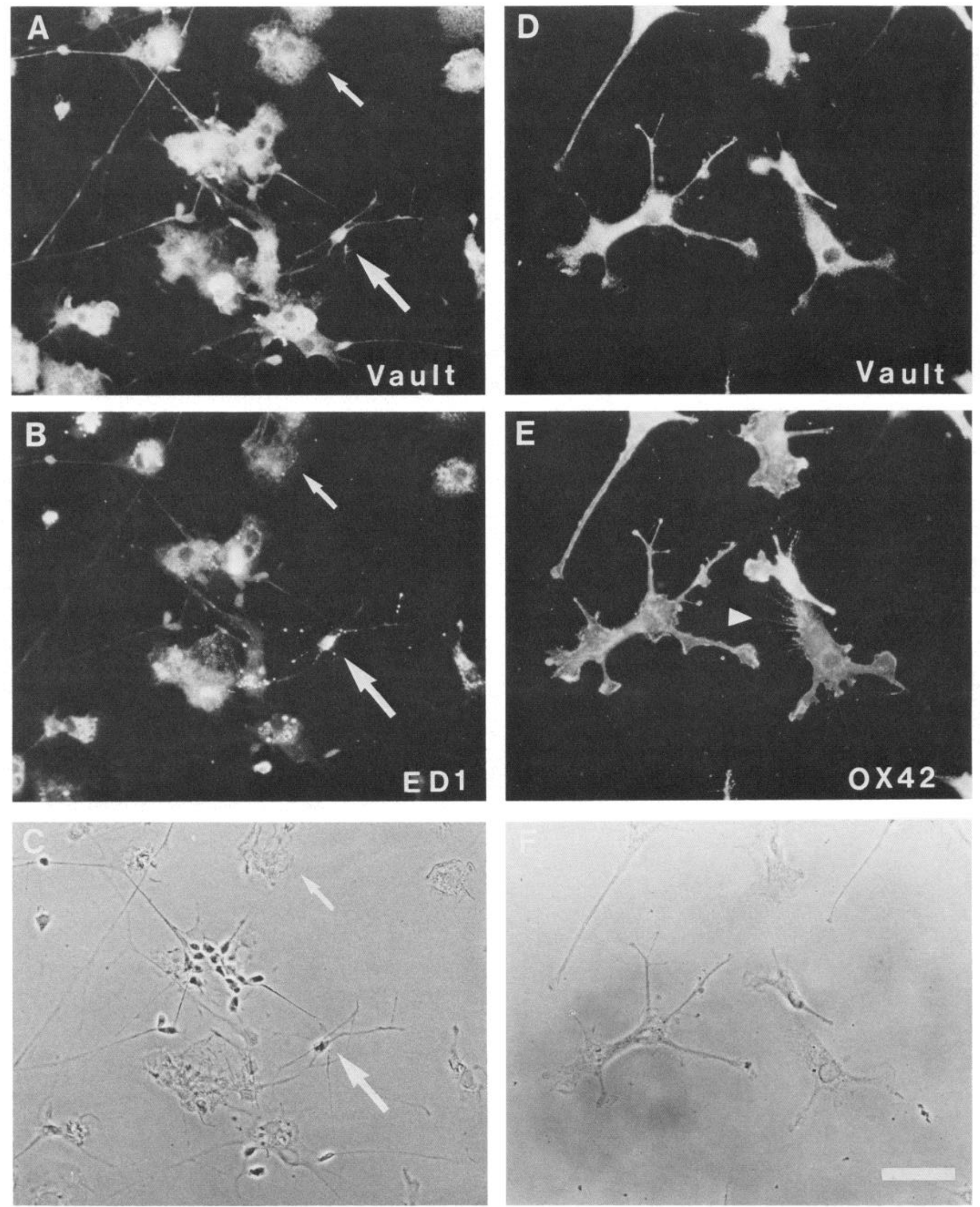

Figure 2. Vault, ED1, and OX42 distribution in cultured microglia. Primary cultured microglia from postnatal day 2 rats were fixed after $14 \mathrm{~d}$ in culture with $-20^{\circ} \mathrm{C}$ methanol and double stained with vault antisera visualized with anti-rabbit rhodamine antibodies and with ED1 or OX42 monoclonal antibodies visualized with anti-mouse fluorescein antibodies. $A-C$, Field double stained with vault antisera $(A)$ and ED1 $(B)$ and phasecontrast view of same field $(C)$. Both ameboid (small arrow) and process-bearing cells (large arrow) display vault and ED 1 immunoreactivity. $D-$ $F$, "Transitional" cells: $D$, Vault antisera; $E$, OX42; $F$, Phase-contrast view of same cells. Note the fine processes (arrowhead) stained with OX42. Scale bar, $10 \mu \mathrm{m}$. 

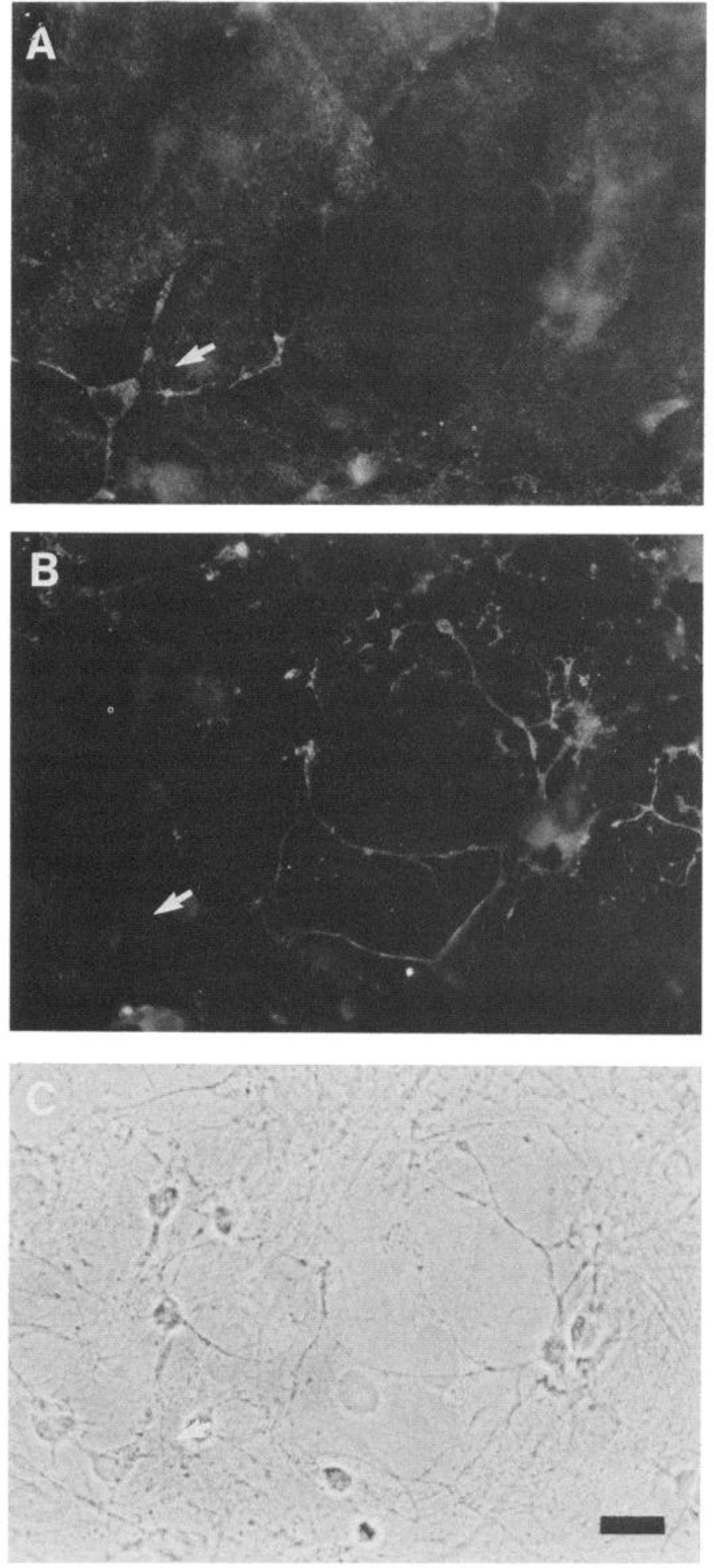

Figure 3. Vault distribution in mixed glial culture. Cells were established from postnatal day 2 rat cortex and fixed with $-20^{\circ} \mathrm{C}$ methanol after $14 \mathrm{~d}$ in culture. Cells were double stained with vault antisera visualized with anti-rabbit rhodamine antibodies and with myelin basic protein monoclonal antibody visualized with anti-mouse fluorescein antibodies. $A$, Diffuse, punctate vault staining was seen throughout the culture, with a brighter, process-bearing cell (arrow). B, Myelin basic protein staining was apparent in regions that displayed only diffuse vault staining. $C$, Phase-contrast image of same field. Scale bar, $10 \mu \mathrm{m}$. ramified cells also displayed ED1 (Fig. $2 B$ ) and OX42 immunoreactivity (not shown). ED1 staining was also cytoplasmic and punctate; however, the granules were somewhat larger than those seen with the vault antiserum and did not colocalize.

Cells that appeared to be transitional between ameboid and ramified cells were also apparent in the 16-d-old (equivalent brain age) microglia cultures (Fig. $2 D-F$ ). These cells displayed bright vault (Fig. $2 D$ ), OX42 (Fig. $2 E$ ), and ED1 immunoreactivity (not shown), as well as $B_{4}$-lectin staining (not shown). $\mathrm{OX} 42$ and $\mathrm{B}_{4}$-lectin displayed diffuse surface labeling and permitted the visualization of fine, straight processes (Fig. $2 E$ for OX42; $\mathrm{B}_{4}$-lectin not shown).

The differentiation of ameboid cells into ramified cells also occurred in mixed glial cultures. These cultures displayed diffuse, punctate vault staining in most cells after 2 weeks in culture. In 2 cell types, however, the vault staining was considerably brighter. Vault immunoreactivity was intense in cells displaying macrophagelike morphology (not shown). In addition, there were small process-bearing cells highly reminiscent of ramified microglia that were distinctly brighter than the surrounding cells (Fig. $3 A$ ). These cells were negative for myelin basic protein immunoreactivity (Fig. $3 B$ ), glial fibrillary acidic protein, and OL28, a putative neuronal marker (not shown).

\section{Immunofluorescence in developing brain}

A summary of the developmental profile of vault, ED1, and OX42 immunoreactivity and $\mathrm{B}_{4}$-lectin staining in brain is shown in Table 1. The reader may find it useful to refer to the table when reading the following results.

\section{Embryonic days 15 and 18}

Vault immunoreactivity was observed in small process-bearing cells in the brain parenchyma of the cerebral hemispheres, midbrain, and spinal cord and in retina (Figs. 4, 5A). The processes were branched and crenulated, often ending upon and wrapping around capillaries (Fig. 5A, large arrow). In many cases, contacted capillaries were also vault positive. Stained cells displaying the morphology described for perivascular ramified microglia (Rio-Hortega, 1932) were also labeled by $\mathrm{B}_{4}$-lectin. In a colocalization study using vault antibody and $\mathrm{B}_{4}$-lectin, the lectin more prominently stained blood vessels (Fig. $5 B$ ) and, in addition, stained many extremely fine, straight processes extending from microglia and vessels perpendicular to the surface of the brain (Fig. 5B, arrowhead). These cells did not display ED1 or OX42 immunoreactivity. Rich vault immunoreactivity was also observed in round, macrophagelike cells in the ventricles, meninges, and posterior chamber of the eye. These macrophagelike cells were also immunoreactive with ED1 and stained with $\mathrm{B}_{4}$-lectin.

\section{Postnatal days 1-4}

Vault immunoreactivity was observed in macrophagelike and ramified cells and in small blood vessels in the early postnatal brain. Ramified microglia positive for vaults were observed in all gray matter regions, and the intensity of staining and number of positive cells increased from day 1 to day 4 (Figs. $6 B, D ; 7 A$ ). Ramified microglia stained intensely with $\mathrm{B}_{4}$-lectin, and weak immunoreactivity was seen with ED1 and OX42. Colocalization of ED1 and OX42 with vault antisera is shown in Figure 6. Macrophagelike vault-positive cells were again observed in the ventricles, choroid plexus, and meninges. In addition, large 

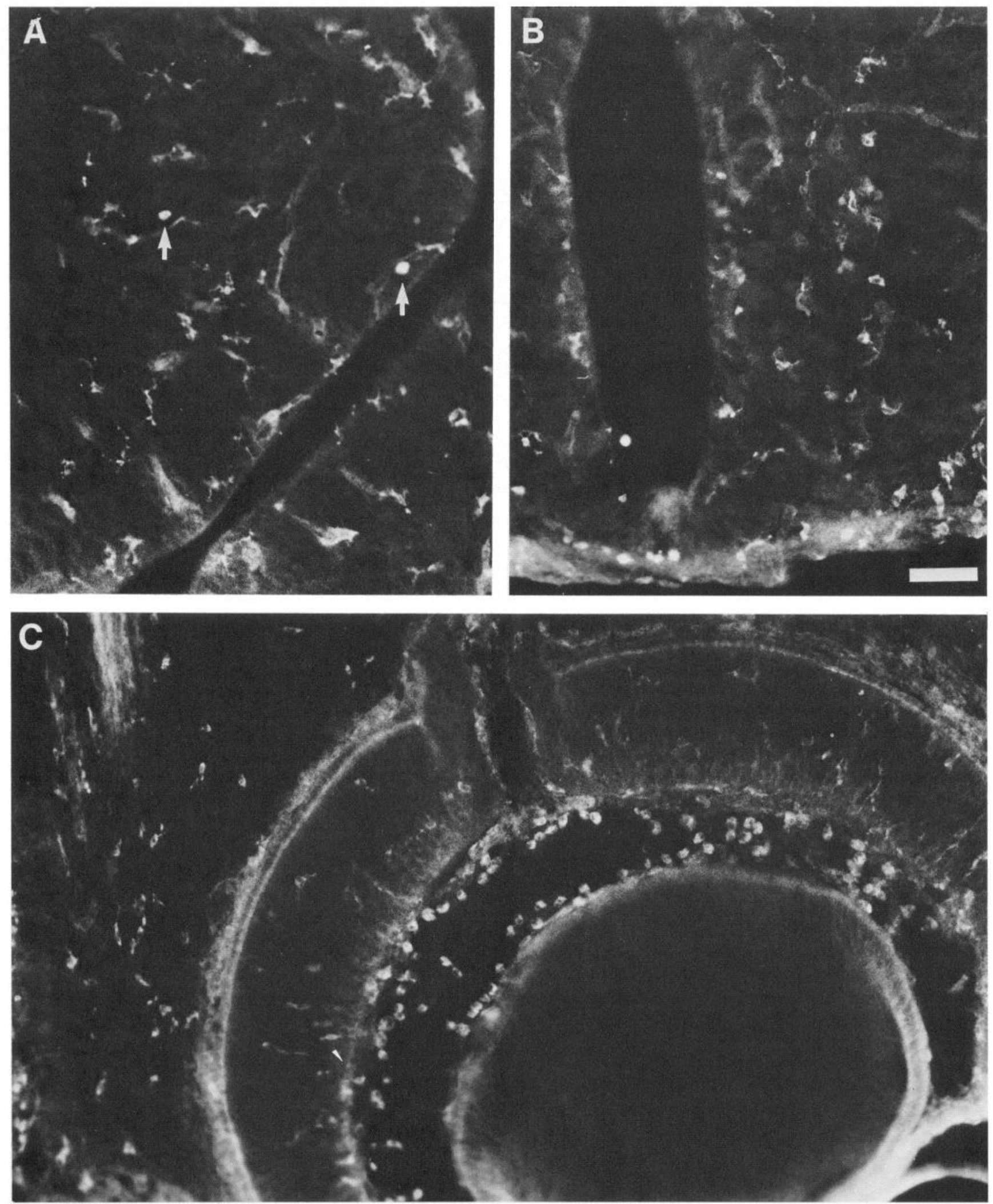

Figure 4. Vault distribution in embryonic day 15 rat CNS. Embryonic day 15 rats were fixed by immersion in $4 \%$ paraformaldehyde, and frozen sections were stained with vault antisera. Many ramified microglia were visualized in cortex $(A)$, spinal cord $(B)$, and retina $(C)$. A few ameboid cells (arrows) were also seen in the brain parenchyma. Large numbers of macrophages were seen in the posterior chamber of the eye (Fig. $3 C$ ), but only ramified cells were in the retina itself. In addition, segments of blood vessels were stained in the brain and spinal cord. Scale bar, $20 \mu \mathrm{m}$. 
Table 1. Time course of expression of microglial markers in brain sections

\begin{tabular}{llllll}
\multicolumn{7}{r}{ E15/18 } & P1-4 & P7 & P14 & P21/180 \\
\hline \multicolumn{7}{l}{ Ameboid microglia } & & & & \\
\multicolumn{7}{r}{ Vault-IR } & $+/-$ & ++++ & +++ & $+/-$ & - \\
ED1-IR & $+/-$ & ++++ & +++ & $+/-$ & - \\
OX42-IR & - & + & ++ & - & - \\
B -lectin & $+/-$ & ++ & ++ & - & - \\
Ramified microglia & & & & \\
Vault-IR & +++ & ++++ & +++ & ++ & + \\
ED1-IR & - & + & + & - & - \\
OX42-IR & - & + & ++ & +++ & ++ \\
B -lectin & ++++ & +++ & ++ & ++ & +
\end{tabular}

Rat brain sections from embryonic day 15 (E15) through postnatal day 180 (P180) were stained with vault antisera visualized with anti-rabbit fluorescein antibodies (Vault-IR), monoclonal antibodies ED1 and OX42 visualized with antimouse fluorescein antibodies (ED1-IR and OX42-IR), and FITC-conjugated Bandeiraea simplicifolia $\mathbf{B}_{\mathbf{4}}$-isolectin ( $\mathbf{B}_{4}$-lectin). Sections were rated subjectively for number of cells stained and intensity of staining on a scale from - to ++++ .

numbers of macrophagelike cells or ameboid microglia appeared in the corpus callosum, internal capsule, and cerebellar medulla, which are all areas containing large numbers of nerve fibers (Fig. $6 F$ ). Vault immunoreactivity was much brighter in the ameboid than in the ramified cells, though the ramified cells were distinctly vault positive relative to background. Ameboid microglia stained with $\mathrm{B}_{4}$-lectin, EDl (Fig. $6 E$ ), and weakly with OX42.

\section{Postnatal day 7}

Vault immunoreactivity at postnatal day 7 was found in all of the same cell types as was seen earlier. However, ramified cells were more highly branched (Fig. $7 B$ ). There were relatively fewer ameboid microglia and more ramified cells. In regions such as the corpus callosum, which previously contained only ameboid cells, cells appeared that looked intermediate between ameboid and ramified microglia (Fig. 8, large arrow). In addition, diffuse vault immunoreactivity was seen in the epithelial cells of the choroid plexus, as well as bright vault staining in Kolmer cells. $\mathbf{B}_{4}$-lectin again stained all the microglial cell types and blood vessels. ED1 immunoreactivity and weak OX42 immunoreactivity was present in the ameboid cells and in the putative transitional cells that appeared to be ameboid microglia developing into ramified microglia. Strong OX42 immunoreactivity was observed in ramified microglia.

\section{Postnatal day 14}

Vault immunoreactivity was greatly diminished by day 14 . Fewer labeled ramified microglia were observed in gray matter, and those remaining were much less intensely stained but more highly branched (Fig. 7C). Very few ameboid microglia remained in the corpus callosum and cerebellar medulla, and ramified microglia were observed in these regions. In addition, blood vessel staining was no longer seen in the cortex, but it was still prominent in the striatum and hippocampus. The only exception to the decreasing vault immunoreactivity in brain was in the choroid plexus, where the cuboidal epithelial cells displayed increased punctate, cytoplasmic staining. $\mathbf{B}_{4}$-lectin in ramified microglia and blood vessels was also diminished. ED1 immunoreactivity was present in a few ameboid and intermediate process-bearing cells in the brain parenchyma, as well as in macrophages in the ventricles, choroid plexus, and meninges. OX42 immunoreactivity was very bright in ramified microglia.

\section{Postnatal days 21 and 180}

Vault immunoreactivity continued to diminish at these later time points. Lightly stained ramified microglia were observed in both gray and white matter at $21 \mathrm{~d}$ and in the adult (Fig. 7D). A few faintly stained blood vessels also remained in the adult striatum. Ameboid microglia completely disappeared by day 21 , and the only macrophagelike cells remaining were a few cells scattered through the choroid plexus and meninges. The vault staining of cuboidal epithelial cells of the choroid plexus increased in intensity from day 14 to day 21 , and from day 21 to day 180 . In addition, diffuse vault immunoreactivity appeared in the granule cell layer of the cerebellum at day 21 , which was still brighter in the adult. ED1 immunoreactivity was seen in the few macrophagelike cells. OX42 and $\mathrm{B}_{4}$-lectin stained ramified microglia throughout the brain, but were diminished in intensity at $21 \mathrm{~d}$ and in the adult.

\section{Western blot analysis}

Western blot analysis of rat cerebral hemispheres using vault antisera showed no developmental difference in the vault content per wet-weight tissue. The size and intensity of staining of the major vault protein p104 was constant with age (Fig. 9).

\section{Discussion}

We have demonstrated that vault immunoreactivity is enriched in ameboid and ramified microglia over other brain cell types,

Figure 5. Vault and $\mathrm{B}_{4}$-lectin distribution in embryonic day 15 brain (metencephalon). Embryonic day 15 rats were fixed by immersion in $4 \%$ paraformaldehyde, and frozen sections were cut. $A$, Vault immunoreactivity was visualized with anti-rabbit rhodamine antibodies. $B$, $B_{4}$-lectin FITC conjugate was visualized in the same section with the fluorescein filter. Vault antisera stained ramified cells (small arrow) and segments of blood vessels (large arrow). $\mathrm{B}_{4}$-lectin also stained ramified cells (small arrow) and blood vessels (large arrow). The $\mathrm{B}_{4}$-lectin staining of blood vessels was much more intense than vault staining. In addition, $\mathrm{B}_{4}$-lectin stained extremely fine fibrils extending from ramified cells and vessels (arrowhead). Scale bar, $10 \mu \mathrm{m}$.

Figure 6. Vault, OX42, and ED1 distribution in postnatal day 2 rat brain. A postnatal day 2 rat was fixed by perfusion with $4 \%$ paraformaldehyde, and frozen sections were double stained with vault antiserum visualized with anti-rabbit rhodamine antibodies and with OX42 or ED1 monoclonal antibodies visualized with anti-mouse fluorescein antibodies. Ramified cells stained with $\mathrm{OX} 42(A)$ and vault antisera $(B)$. A ramified cell stained with ED1 $(C)$ and vault antisera $(D)$. Amehoid cells over the corpus callosum stained with ED1 $(E)$ and vault antisera $(F)$. Scale bar: $5 \mu \mathrm{m}$ for $A-$ $D ; 15 \mu \mathrm{m}$ for $E, F$.

Figure 7. Vault distribution in rat cortex with development. Postnatal rats were fixed by perfusion with $4 \%$ paraformaldehyde, and frozen sections were stained with vault antisera visualized with anti-rabbit fluorescein antibody. Ramified microglia stained in the cerebral cortex in rats aged 3 $\mathrm{d}(A), 7 \mathrm{~d}(B), 14 \mathrm{~d}(C)$, and $180 \mathrm{~d}(D)$. The apparent intensity of staining diminished from 7 to $14 \mathrm{~d}$, and from 14 to $180 \mathrm{~d}$, while the branching of the processes increased. A cell that appears to be traversing a blood vessel wall is seen in $B$ (arrow). Scale bar, $5 \mu \mathrm{m}$. 

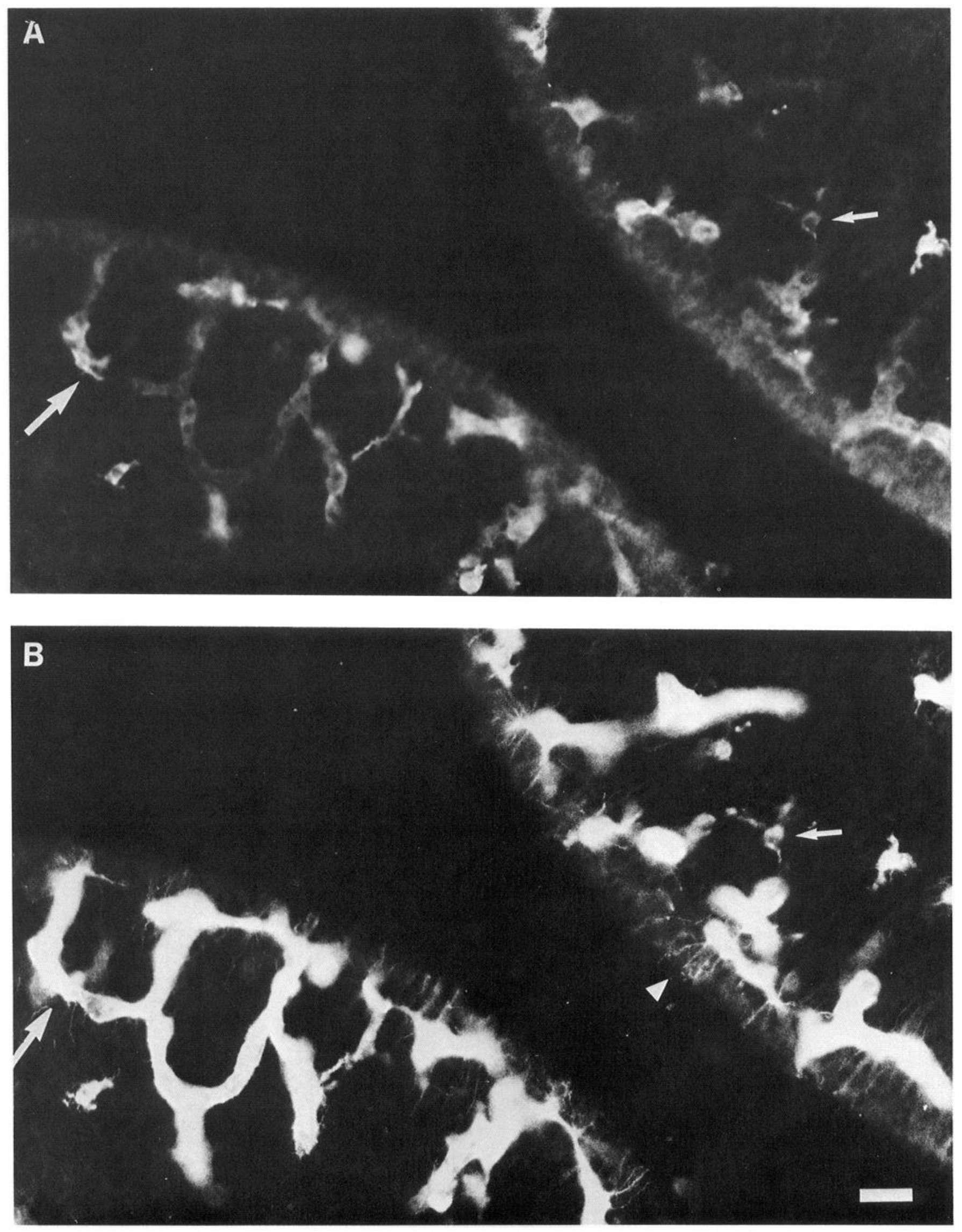


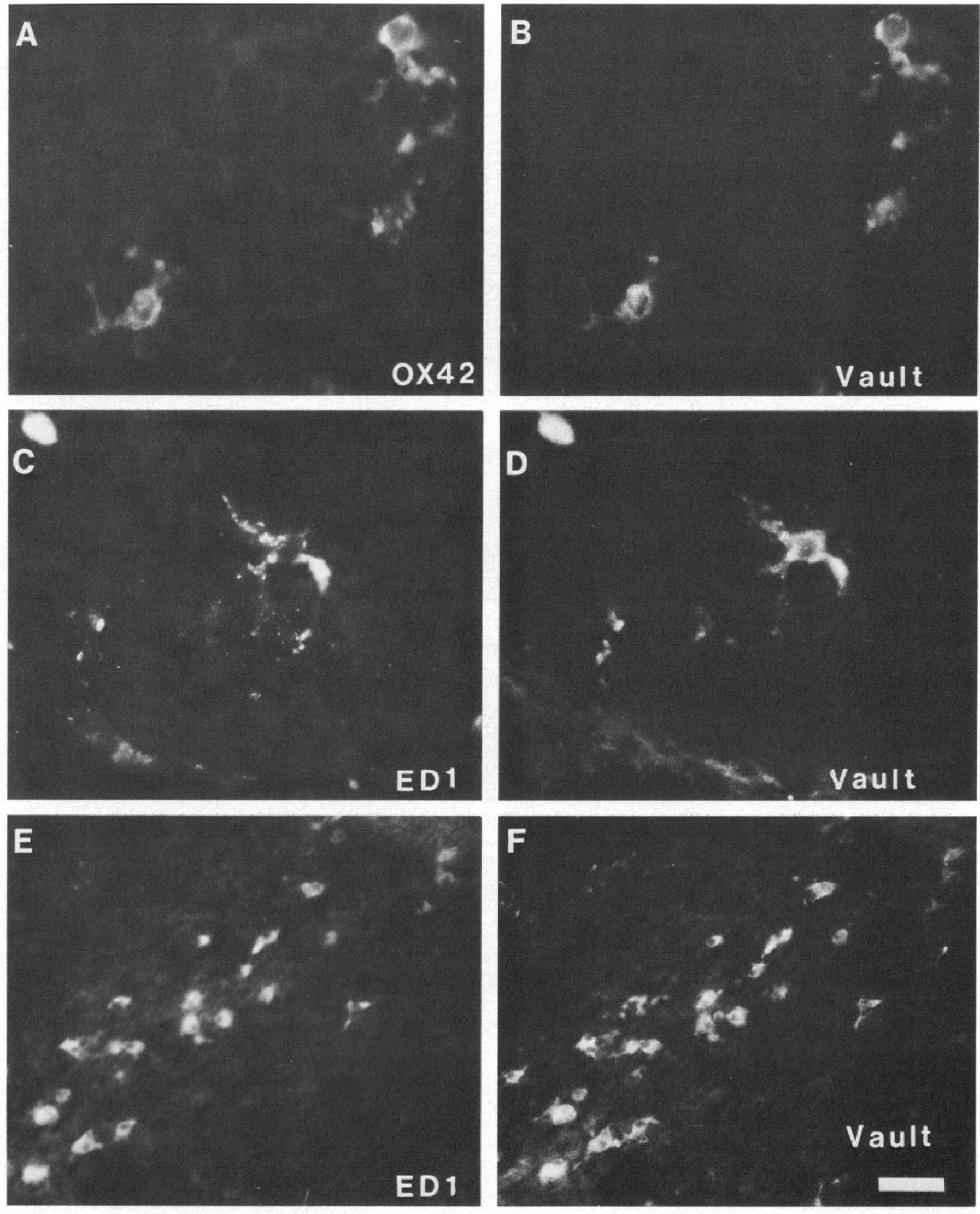



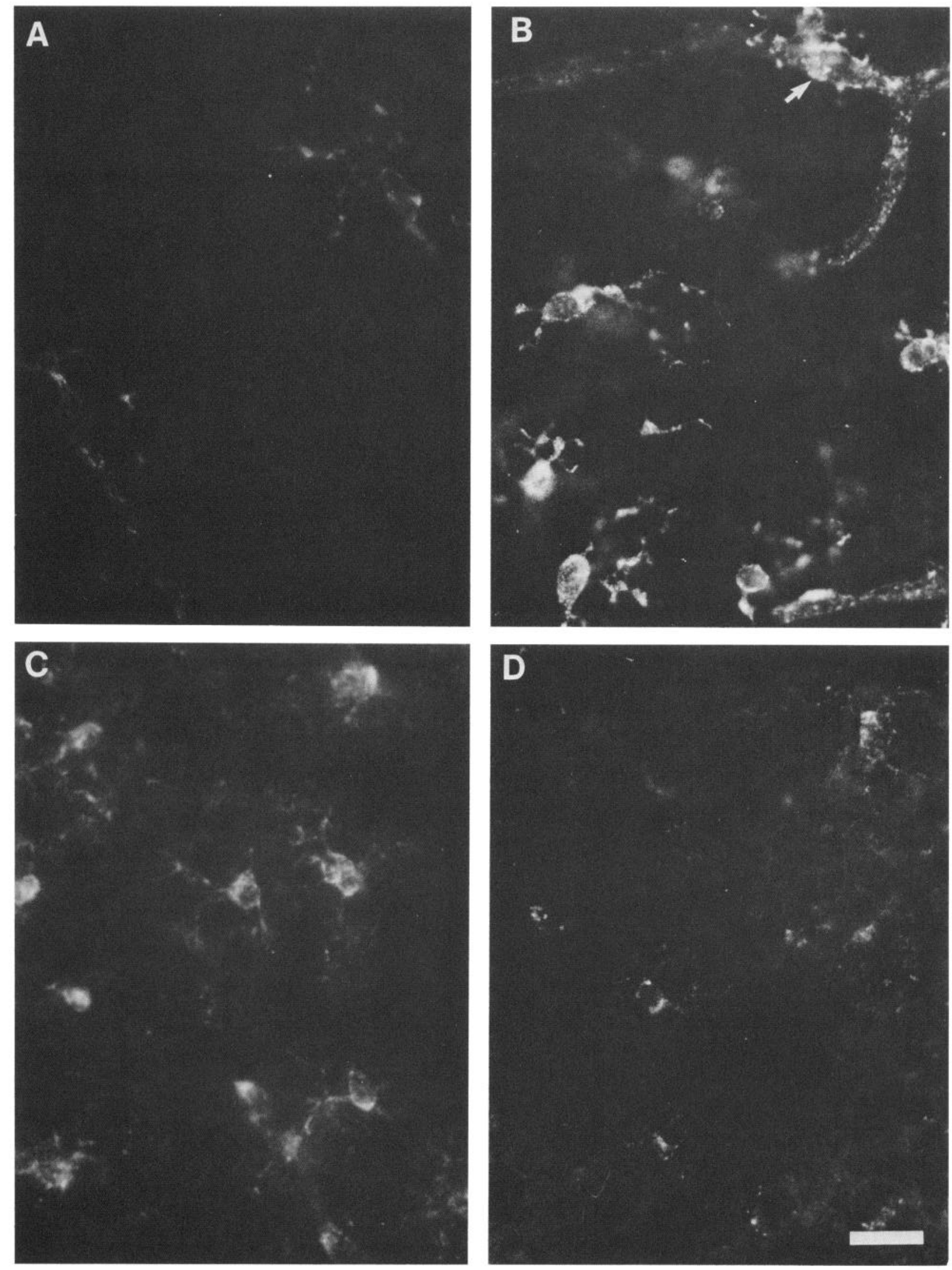


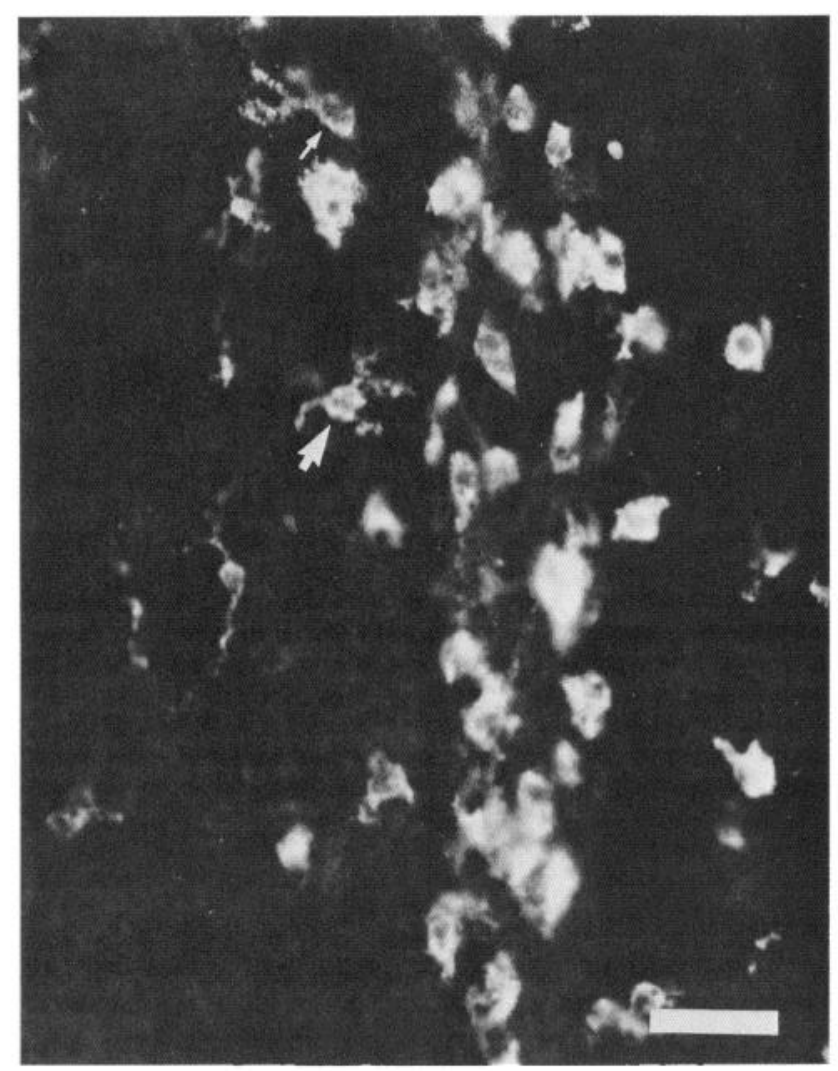

Figure 8. Vault distribution in postnatal day 7 corpus callosum. Postnatal day 7 rats were fixed by perfusion with $4 \%$ paraformaldehyde, and frozen sections were stained with vault antisera visualized with antirabbit fluorescein antibody. Ameboid microglia were abundantly seen over the corpus callosum at this age. A few ramified (small arrow) and "transitional" cells (large arrow) are also apparent. Scale bar, $10 \mu \mathrm{m}$.

both in culture and in brain sections. The morphology, localization, phagocytic activity (data not shown), and colocalization with the established microglial markers ED1, OX42, and Bandeiraea simplicifolia $\mathbf{B}_{4}$-lectin (see Materials and Methods) positively identify the vault-immunoreactive cells as microglia. The ability of the cultured microglia to exhibit a ramified morphology after 1 week in culture shows these cells are not simply macrophages from blood vessels ruptured during dissection. Furthermore, vault immunoreactivity, as a very early microglial marker, provides new insight regarding the much-debated origin of ramified microglia.

The developmental profile of vault immunoreactivity in rat brain sections suggests that microglia enter the brain by 2 different routes, with different time scales for each. The first migration begins before embryonic day 15 and subsides between postnatal days 7 and 14 . These cells appear to enter from blood vessels (Figs. $4 A, 6 B$ ) and display a ramified morphology as soon as they are detected in the brain. The vault immunoreactivity in the blood vessels at this time suggests that macrophages may differentiate into ramified cells at or in the vessel walls before migrating into the brain tissue. It is quite clear that they do not develop from ameboid microglia in the brain because the ramified cells can be detected before the postnatal influx of ameboid cells.

The second microglial migration occurs in the first postnatal week, when ameboid microglia appear in the corpus callosum

\section{$\begin{array}{llllllllllll}1 & 2 & 3 & 4 & 5 & 6 & 7 & 10 & 14 & 21 & 180 & V\end{array}$}

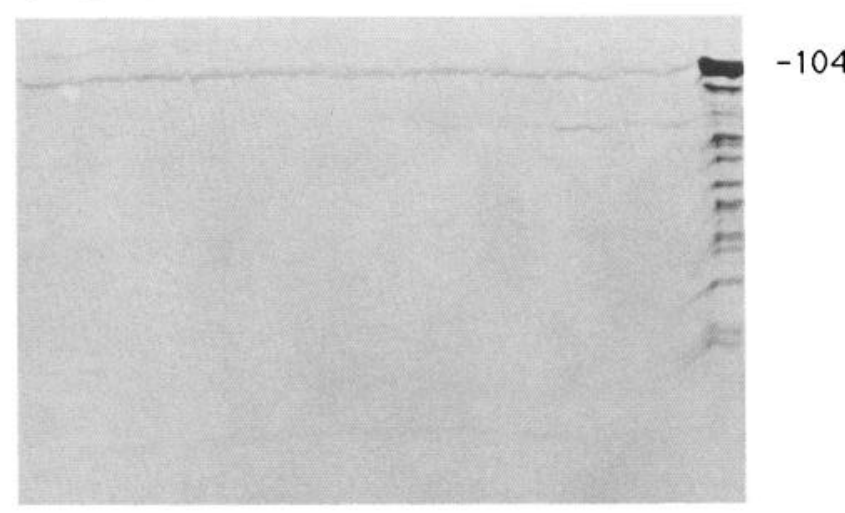

Figure 9. Immunoblot analysis of vault distribution in rat cerebral hemispheres with age. Equal amounts of extracts were resolved on a $10 \%$ SDS-polyacrylamide gel, transferred to nitrocellulose, and subjected to immunoblot analysis using vault antisera. Lanes $1-11$ contained samples from postnatal day $1,2,3,4,5,6,7,10,14,21$, and 180 rats, respectively. Lane 12 contains purified vault standard. A band at $104 \mathrm{kDa}$ was seen at all ages.

and other large fiber tracts. These cells also presumably enter from the blood; however, blood vessels in these regions are not stained by vault antisera. It is this population of cells that have been previously demonstrated to be derived from circulating monocytes (Ling et al., 1980). Transitional forms of ameboid microglia apparent in these tracts are labeled with both vault antisera and ED1 (Fig. 6C,D); therefore, it is quite likely that ameboid cells differentiate into ramified microglia. Ameboid microglia, however, do not appear to be the sole source of ramified microglia in the brain.

The finding that the capillaries underlying the perivascular ramified microglia are also vault immunoreactive suggests that phagocytic pericytes may be the precursors of these cells. This is not, in fact, a new concept. Mori and Leblond (1969) suggested that pericytes could be one source of microglia based upon their observation of silver carbonate-stained cells on the capillary wall that resembled microglia in morphology. A number of other investigators have subsequently lent support to this notion (Baron and Gallego, 1972; Brichova, 1972; Sturrock, 1974; Hager, 1975; Boya, 1976), though Imamoto and Leblond (1978) reported they could find no evidence that pericytes migrated into brain tissue.

What is the origin of the pericytes? Mori (1972) has suggested that these cells, like the ameboid microglia, may have a monocyte origin. He postulated that pericytes are blood cells that have entered the pericytal space. In support of this view, Ling (1981) pointed out that the pericytes are phagocytes, as evidenced by the uptake of circulating HRP (Cancilla et al., 1972) and colloidal carbon particles (Ling, 1978).

The present study supports the notion that ramified microglia, like ameboid microglia, originate from monocyte lineage. The use of multiple markers throughout the course of brain development allowed us to visualize time periods in which expression of these markers overlapped. Vault antisera and $\mathrm{B}_{4}$-lectin detected ramified microglial cells from embryonic day 15 through adulthood, though vault immunoreactivity greatly diminished in intensity after postnatal day 7 . At postnatal day 2 , the ramified microglia began to express OX42, the complement C3bi recep- 
tor, as well as vaults and lectin binding in double-label experiments. In addition, some EDI-positive cells between postnatal day 7 and 14 displayed processes, suggesting that some ramified microglia do indeed differentiate from ameboid cells, but lose the EDI antigen in the process of differentiation. Indeed, other monocyte and/or macrophage markers have labeled ramified microglia. Perry et al. (1985) demonstrated that the macrophage-specific antigen $\mathrm{F} 4 / 80$, the complement type 3 receptor (Mac-1), and the trypsin-resistant $\operatorname{IgG} 1 / \operatorname{IgG} 2 \mathrm{~b}$ mouse-Fc receptor (2.4G2) were all expressed in macrophages and microglia in the developing and adult mouse brain. Esiri and McGee (1986) similarly reported that monoclonal antibody EMB/11 raised against human lung macrophages recognized both macrophages and ramified microglia in normal and diseased human brain. Further evidence that ramified microglial cells may also be derived from monocytes comes from the work of Hickey and Kimura (1988). They used rat bone marrow chimeras to show that perivascular microglial cells are bone marrow derived.

The absence of other monocyte/macrophage markers has been given as evidence refuting the monocytic origin of ranified microglia (Fujita et al., 1978; Oehmichen et al., 1979; Wood et al., 1979; Tsuchihashi et al., 1981; Matsumoto and Ikuta, 1985; Sminia et al., 1987). However, in a comprehensive study of 39 monoclonal antibodies raised against monocytes or macrophages, Keller et al. (1989) showed wide heterogeneity in the expression of the antigens by cultured bone marrow macrophages. This study clearly points out that some epitopes may display variability in expression even in a pure population of resting macrophages. It has also been recognized that there is developmental expression of some antigens, and that cells may be induced to express the antigens under certain conditions. Suzumura et al. (1987) demonstrated, for example, cxpression of class I and class II (Ia) antigens on $\gamma$-interferon-treated, but not unstimulated cultured brain macrophages. Macrophages are obviously a heterogeneous population with regard to their antigenic properties, and therefore, the absence of some macrophage/monocyte markers clearly cannot be used as evidence that microglia are not derived from monocytes.

Evidence that ameboid cells can differentiate into ramified cells comes from 2 different types of studies. First, peritoneal macrophages injected into the rabbit brain express processes like ramified microglia (Oehmichen et al., 1979). Second, cultured macrophages from the brain can be induced to develop processes with retinoic acid and dimethyl sulfoxide (Giulian and Baker, 1986). In fact, in the present study, some ameboid cells spontancously differentiated after 1 week in culture into cells with long processes resembling ramified microglia (Figs. 2, 3). Similar to microglia seen in sections, the cultured ramified microglia contained less vault immunoreactivity than the ameboid cells. In contrast, however, both ramitied and ameboid microglia expressed EDl and OX42 immunoreactivity in culture, whereas in vivo, ameboid cells did not stain well with OX42, and transitional, but not fully ramified cells stained with ED1. Apparently, the regulation of these antigens present in vivo is lost in the cultured cells.

The presence of a constant amount of the p104 major vault protein with age indicated by Western blot was somewhat surprising in light of the developmental changes seen in the immunofluorescence studies. It is very likely that, though microglia contain more vault immunoreactivity than other brain cells, the majority of cells in the brain contain lower vault levels that are constant with age. In support of this view, mixed glial cultures display bright staining in microglia, while all other cells contain diffuse vault staining (Fig. $3 A$ ).

Vault immunoreactivity has helped clarify issues regarding the origin of microglial cells. What is the developmental expression of vaults in the brain telling us about vault function? Vault expression is highest in the adult choroid plexus and in ameboid microglia. Vault expression is also high during the establishment of ramified microglia in the brain, but diminishes after the processes are fully arborized and set in place. Characteristics in common between ameboid microglia and microvilli of choroid plexus cells are motility, the ability to undergo dramatic shape changes, and secretion. Colocalization studies of vault immunoreactivity with actin in fibroblasts showed that vaults are often associated with actin bundles and at the point of attachment of actin cables with the membrane (Kedersha, unpublished observations). These data, taken together, suggest a role for vaults in cytoskeletal organization and attachment of actin filaments, with vault concentration being the highest in the most motile, plastic cell types.

\section{References}

Baron M, Gallego A (1972) The relation of the microglia with the pericytes in the cat cerebral cortex. Z Zellforsch Mikrosk Anat 128: $42-57$.

Boya J (1976) An ultrastructural study of the relationship between pericytes and cerebral macrophages. Acta Anat 95:598-608.

Brichova $\mathrm{H}$ (1972) Contribution to the question of the existence and function of microglia cells in the rat central nervous system. Folia Morphol (Praha) 20:85-87.

Cancilla PA, Baker RN, Pollock PS, Frommes BS (1972) The reaction of pericytes of the central nervous system to exogenous protein. Lab Invest 26:376-383.

Dijkstra CD, Dopp EA, Joling P, Kraal G (1985) The heterogeneity of mononuclear phagocytes in lymphoid organs: distinct macrophage subpopulations in the rat recognized by monoclonal antibodies ED1, ED2 and ED3. Immunology 54:589-599.

Esiri MM, McGee JOD (1986) Monoclonal antibody to macrophages $(\mathrm{EMB} / 11)$ labels macrophages and microglial cells in human brain. $\mathrm{J}$ Clin Pathol 39:615-621.

Fujita S, Tsuchihashi Y, Kitamura T (1978) Absence of hematogenous cells in the normal brain tissue as revealed by leukocyte-specific immunofluorescent staining. J Neuropathol Exp Neurol 38:369-376.

Fukio Y, Yumura S, Yumura TK (1987) Agar-overlay immunofluorescence: high-resolution studies of the cytoskeletal components and their changes during chemotaxis. Meth Cell Biol 28:347-356.

Giulian D, Baker TJ (1985) Peptides released by ameboid microglia regulate astroglial proliferation. J Cell Biol 101:2411-2415.

Giulian D, Baker TJ (1986) Characterization of ameboid microglia isolated from developing mammalian brain. J Neurosci 6:2163-2178.

Gracber MB, Streit WJ, Kreutzberg GW (1988) Axotomy of the rat facial nerve leads to increased CR3 complement receptor expression by activated microglial cells. J Neurosci Res 21:18-24.

Hager $\mathrm{H}$ (1975) EM findings on the source of reactive microglia on the mammalian brain. Acta Neuropathol [Suppl] (Berl) 6:279-283.

Hickey WF, Kimura H (1988) Perivascular microglial cells of the CNS are bone marrow-derived and present antigen in vivo. Science 239: $290-292$

Imamoto K, Leblond CP (1978) Radioautographic investigation of gliogenesis in the corpus callosum of young rats II. Origin of microglial cells. J Comp Neurol 180:139-164.

Innocenti GM, Koppel H, Clarke S (1983a) Transitory macrophages in the white matter of the developing visual cortex. I. Light and electron microscopic characteristics and distribution. Dev Brain Res $11: 39-53$

Innocenti GM, Clarke S, Koppel H (1983b) Transitory macrophages in the white matter of the developing visual cortex. Il. Development and relations with axonal pathways. Dev Brain Res 11:55-66. 
Kedersha NL, Rome LH (1986a) Isolation and characterization of a novel ribonucleoprotein particle: large structures contain a single species of small RNA. J Cell Biol 103:699-709.

Kedersha NL, Rome LH (1986b) Preparative agarose gel electrophoresis for the purification of small organelles and particles. Anal Biochem 156:161-170.

Kedersha NL, Miquel M-C, Bittner D, Rome LH (1990) Vaults: II. Ribonucleoprotein structures are highly conserved among higher and lower eukaryotes. J Cell Biol 110:895-901.

Keller R, Joller PW, Keist R (1989) Surface phenotype of rat bone marrow-derived mononuclear phagocytes. Cell Immunol 120:277285.

Laemmli UK (1970) Cleavage of structural proteins during the assembly of the head of bacteriophage T4. Nature 277:680-685.

Ling EA (1978) Electron microscopic studies of macrophages in Wallerian degeneration of rat optic nerve after intravenous injection of colloidal carbon. J Anat 126:111-121.

Ling EA (1981) The origin and nature of microglia. Adv Cell Neurobiol 2:33-82.

Ling EA, Penney D, Leblond CP (1980) Use of carbon labelling to demonstrate the role of blood monocytes as precursors of the "ameboid cells" present in the corpus callosum of postnatal rats. J Comp Neurol 193:631-657.

Matsumoto Y, Ikuta F (1985) Appearance and distribution of fetal brain macrophages in mice. Immunohistochemical study with a monoclonal antibody. Cell Tissue Res 239:271-278.

McCarthy K, de Vellis J (1980) Preparation of separate astroglial and oligodendroglial cell cultures from rat cerebral tissue. J Cell Biol 85: 890-902.

Mori S (1972) Uptake of [ $\left.{ }^{3} \mathrm{H}\right]$ thymidine by corpus callosum cells in rats following a stab wound of the brain. Brain Res 46:177-186.

Mori S, Leblond CP (1969) Identification of microglia in light and electron microscopy. J Comp Neurol 135:57-80.

Oehmichen M, Wietholter H, Gruninger H, Gencic M (1979) Features and distribution of intracerebrally injected peritoneal macrophages. Exp Pathol 17:71-76.
Perry VH, Hume DA, Gordon S (1985) Immunohistochemical localization of macrophages and microglia in the adult and developing mouse brain. Neuroscience 15:313-326.

Porath J (1974) General methods and coupling procedures. Meth Enzymol 34:13-30.

Rio-Hortega, del P (1932) Microglia. In: Cytology and cellular pathology of the nervous system, Vol 2 (Penfield W, ed), pp 483-534. New York: Hoeber.

Robinson AP, White TM, Mason DW (1986) Macrophage heterogeneity in the rat as delineated by two monoclonal antibodies MRC $\mathrm{OX}-41$ and MRC OX-42, the latter recognizing complement receptor type 3. Immunology 57:239-247.

Sminia T, DeGroot CJA, Dijkstra CD, Koetsier JC, Polman CH (1987) Macrophages in the central nervous system of the rat. Immunobiology 174:43-50.

Streit WJ, Kreutzberg GW (1987) Lectin binding by resting and reactive microglia. J Neurocytol 16:249-260.

Sturrock RR (1974) Histogenesis of the anterior limb of the anterior commissure of the mouse brain. III. An electron microscopic study of gliogenesis. J Anat 117:37-53.

Suzumura A, Mezitis SGE, Gonatas NK, Silberberg DH (1987) MHC antigen expression on bulk isolated macrophage-microglia from newborn mouse brain: induction of Ia antigen expression by $\gamma$-interferon. J Neuroimmunol 15:263-278.

Towbin H, Staehdin T, Gordon J (1979) Electrophoretic transfer of proteins from polyacrylamide gels to nitrocellulose sheets: procedure and some applications. Proc Natl Acad Sci USA 76:4350-4354.

Tsuchihashi Y, Kitamura T, Fujita S (1981) Immunofluorescence studies of monocytes in the injured rat brain. Acta Neuropathol 53: 213-219.

Wood GW, Gollahon KA, Tilzer SA, Vats T, Morantz RA (1979) The failure of microglia in normal brain to exhibit mononuclear phagocyte markers. J Exp Neuropathol Exp Neurol 38:369-376. 